\title{
As interferências da Língua Materna e o aprendizado do Alemão como Língua Estrangeira por crianças bilíngües
}

Karen Pupp Spinassé*

\begin{abstract}
A learner's mother tongue influences the acquisition or learning of another language, regardless of whether we are dealing with a second or a foreign language. But there are other factors influencing these processes. One can therefore only analyze these interferences by taking into account certain factors which include elements transferred from the mother tongue, elements from other languages that the learner has already learned, and elements coming from the language being learned or acquired. Moreover, these so-called interferences do not only occur at the linguistic level, but also at the extralinguistic level. This paper describes and discusses these factors in order to describe the process of learning German as a foreign language in Brazil and its peculiarities with regard to bilingual education. Through the description and analysis of empirical data and on the basis of the theory of the "great hypotheses", this text aims at better understanding the relationship between first and foreign/second language and their mutual interferences.
\end{abstract}

Keywords: Interference; Second language acquisition; Foreign language learning; Bilingual education.

A autora é bolsista Pós-Doc do CNPq na Universidade Federal do Rio Grande do Sul. 
Zusammenfassung: Die Muttersprache beeinflusst den Erwerbs- oder Lernprozess einer weiteren Sprache - unabhängig davon, ob es sich dabei um eine Zweit- oder um eine Fremdsprache handelt. Es gibt aber auch andere Faktoren, die bei diesen Prozessen eine wichtige Rolle spielen. Daher kann man den Einfluss anderer Sprachen beim Erwerb oder Erlernen einer weiteren Sprache nur dann richtig einschätzen, wenn mehrere Faktoren für die Analyse untersucht werden. Der hier beschriebene Ansatz bezieht sich daher sowohl auf Elemente, die aus der Muttersprache transferiert werden, als auch auf solche aus anderen zuvor erlernten Sprachen und schließlich auf Elemente aus der Zielsprache selbst. Daneben sollte nicht vergessen werden, dass diese sogenannten Interferenzen nicht nur auf linguistischer, sondern auch auf extra-linguistischer Ebene vorkommen. Der vorliegende Artikel zielt darauf ab, diese Faktoren zu beschreiben und zu diskutieren, um den Lernprozess des Deutschen als Fremdsprache in Brasilien sowie seine Besonderheiten in Bezug auf die bilinguale Erziehung zu charakterisieren. Durch die Beschreibung und die Analyse empirischer Daten soll, ausgehend von der Theorie der Großen Hypothesen, über die Beziehungen zwischen Erst- und Fremd- bzw. Zweitsprache sowie deren gegenseitigen Interferenzen reflektiert werden.

Stichwörter: Interferenz; Zweitsprachenerwerb; Fremdsprachenlernen; bilinguale Erziehung.

Palavras-chave: Interferência; Aquisição de segunda língua; Aprendizagem de língua estrangeira; Educação bilíngüe.

\section{Introdução}

A língua materna (L1) exerce influência inquestionável no aprendizado de línguas estrangeiras (LE). Muitas vezes, os alunos "transferem" elementos da língua materna para a língua-alvo. Esses elementos transferidos podem trazer vantagens e desvantagens no processo de aprendizado. A língua materna, entretanto, não desempenha esse papel sozinha. Durante muito tempo ela foi vista como o único fator influente no processo de aquisição de línguas estrangeiras ou de segundas línguas (L2). Contudo, elementos de outros sistemas lingüísticos já adquiridos, ou anteriormente estudados, bem como elementos da própria língua-alvo, também são levados em considera- 
ção como estratégia de aprendizado. Apesar disso, ainda lança-se mão, freqüentemente, apenas de informações da língua materna, quando se quer analisar os desvios lingüísticos no processo de aprendizagem.

Nesse artigo, a autora busca tratar do conceito "interferência", a fim de discutir a diferenciação entre este e o conceito de "erro", assim como a influência concreta da língua materna em detrimento de outros fatores. Contudo, para que a teoria possa ser apresentada sob a luz da prática, serão apresentados, a título de ilustração, no final do texto, alguns exemplos retirados de testes feitos com alunos monolíngües e bilíngües no Brasil, quando do aprendizado do alemão-padrão como língua estrangeira ( $\mathrm{DaF}$ - Deutsch als Fremdsprache). ${ }^{1}$

Enquanto os alunos monolíngües aqui pesquisados possuem apenas o português como L1, os alunos bilíngües estudados falam, além do português, uma outra língua materna, o "hunsrückisch", que historicamente está intimamente ligado e estruturalmente muito próximo da língua-alvo em questão. ${ }^{2}$ Por isso, parte-se sempre do pressuposto, que os falantes bilín-

1 O presente artigo tem como ponto de partida a tese de doutoramento da autora, defendida em fevereiro de 2005 e publicada em livro em junho de 2005 (Pupp Spinassé 2005).

2 Como o hunsrückisch é considerado um sistema lingüístico independente, por mais que existam muitas semelhanças com o alemão-padrão e, ao mesmo tempo, muitos empréstimos do português, tratamo-lo aqui também dessa forma. Os alunos pesquisados no contexto sulino preenchem vários pré-requisitos que os caracterizem como falantes nativos do hunsrückisch (como domínio total do hunsrückisch, primeira língua na ordem de aquisição, ou aquisição após o português, mas ainda na infância, língua com a qual se identificam, língua dos pais, de casa, da comunidade, etc.), além de possuírem também o português dentro dessas mesmas condições. Por isso, consideramos esses alunos como bilíngües. Em poucas linhas torna-se difícil definir bem e fazer clara a denominação, mas algumas fontes ajudam a entender melhor a situação de nativos e de bilíngües desses falantes, como Altenhofen 1996, 2001, 2002; Pupp Spinassé 2006; Altenhofen \& Pupp Spinassé no prelo; Ziegler 1996 entre outros. Nesse sentido, os projetos ALMA-H, ESCRITHU e EAMHP, da Universidade Federal do Rio Grande do Sul, trabalham para legitimar esse caráter, produzindo também considerações a respeito (vide Pupp Spinassé no prelo) 
gües aprenderiam melhor o alemão-padrão, unicamente porque já trariam consigo um "pré-conhecimento" da LE a ser adquirida (mais possibilidades de transfer). O nosso intuito é, entretanto, observar o comportamento da L1 em situação de aprendizagem, considerando também outros fatores, como o contexto, a motivação e a empatia.

Para que se possa entender melhor a questão da interferência e da influência da L1, iniciaremos a parte teórica com a descrição das "grandes hipóteses" que dissertam a respeito da relação L1 x L2 (LE) no momento da aquisição da última. Essas teses, porém, não determinaram a análise. Pelo contrário, tentou-se adequar a análise a partir de seus resultados a um modelo de tese para observar a validade das mesmas. O capítulo 2 visa apenas a dar o apanhado histórico de hipóteses dos estudos da aquisição de L2 - elas não valem, porém, como verdades absolutas para as análises, sendo simplesmente norteadoras.

\section{As chamadas "grandes hipóteses"3}

$\mathrm{Na}$ teoria de aquisição de línguas, na Alemanha, fala-se de muitas teses importantes e interessantes, que se ocupam do processo de aprendizado de uma língua (vide Edmondson/ House 1993; Schloter 1992; Wode 1985). Elas se complementam nos diversos aspectos desse complexo processo, que é constantemente marcado por inúmeros fatores. Dentre elas existem, no entanto, três determinadas teses lingüísticas e didáticas de especial importância, quando se trata da análise do processo de aquisição de uma língua, já que, normalmente, os pressupostos teóricos de uma dessas assim denominadas grandes hipóteses estarão por trás da análise. Elas são a

3 Cabe aqui talvez discorrer brevemente sobre a motivação da escolha bibliográfica. Apesar de haver pesquisas mais atuais a respeito da aquisição de L2 (por exemplo, Griesshaber 2002), essas trazem como novidade, geralmente, apenas novas aplicações empíricas - como faremos também no presente artigo. A teoria, contudo, costuma ser reproduzida, ou seja, os autores atuais citam, em grande parte, as mesmas fontes originais, sem acrescentar novos dados. Por isso, sem haver grandes mudanças significantes na discussão teórica, e por visarmos uma caracterização diacrônica, consideramos válido citar quem o disse primeiro. 
"Kontrastivbypothese" (Hipótese da Análise Contrastiva, ou simplesmente Hipótese Contrastiva), a "Identitätshypothese" (Hipótese de "Identidade") e a "Interlanguage-Hypothese" (Hipótese de Interlíngua).

A Hipótese Contrastiva, também denominada como Interferenzhypothese (Hipótese da Interferência), traz como base os pressupostos behavioristas da teoria de aprendizado. Os pioneiros dessa tese foram FrIEs (1945) e LADO (1957), e uma das maiores contribuições dela foi a discussão sobre os "erros" no processo de aprendizado. Até então, os erros não haviam ganhado a devida posição como um tema na teoria e não eram vistos como um fenômeno a ser pesquisado (cf. SCHLOtER 1992: 3; HeINDRICHS/GESTER/ KELZ 1980: 103).

LADO observou em seus estudos, que alunos com uma mesma língua materna faziam os mesmos erros na língua-alvo. De acordo com a Hipótese Contrastiva, a aquisição de uma L1 e de uma L2 não ocorrem da mesma forma: quando da aquisição de uma L2, o aprendiz já possui uma L1, e sendo assim, ele se utilizaria, automaticamente, do seu conhecimento lingüístico já existente (enquanto na aquisição de L1 não há um conhecimento lingüístico pré-existente). Segundo essa vertente, então, a(s) L1 influencia $(m)$ o processo de aquisição de uma outra língua, porque regras e elementos lingüísticos casualmente idênticos nas duas línguas levarão a um aprendizado mais fácil e sem erros, enquanto regras e elementos lingüísticos diferentes levam a dificuldades na aprendizagem e, conseqüentemente, a erros (cf. BAusch/Kasper 1979; KnAPP/KNAPP-PotTHOFF 1982).

LADO (1957: 2) escreve: "Those elements that are similar to his native language will be simple for him, and those elements that are different will be difficult." Se há um caso de semelhança, a regra da língua materna será transferida para a língua-alvo e o resultado será positivo. A isso damos o nome de "transfer". Caso, porém, elementos e regras divergentes sejam confrontados, o aluno recorrerá à língua materna, não achará uma solução para o seu conflito e, certamente, cometerá um erro. Isso resulta em uma transferência negativa, a saber, "interferência". Ambos os termos derivam basicamente de um mesmo produto; devido ao seu valor, porém, eles são denominados de formas diferentes.

Por causa disso, essa tese contrastiva também é chamada de Hipótese da Interferência. Segundo ela, o aprendizado de uma língua estrangeira é 
facilitado pelas semelhanças com a língua materna. Deve-se chamar a atenção dos alunos, porém, para as diferenças entre ambos os códigos em sala de aula, para que essas possam ser reconhecidas e, conseqüentemente, para que as interferências possam ser evitadas. O objetivo é criar uma "aula preventiva", na qual se trabalhe uma "profilaxia" dos erros. Acreditava-se, com esta tese, que se podiam prever todos os erros possíveis na aquisição de uma língua estrangeira e, com isso, evitá-los (cf. SCHLOTER 1992: 8).

No entanto, essa tese deixa várias lacunas, como é argumentado em Bausch \& Kasper (1979), Edmondson \& House (1993) e Steinmüller (2001). Primeiramente, nem todos os erros na língua-alvo resultam, necessariamente, de um transfer da língua materna; segundo, as interferências podem ter vindo da transferência de estruturas da própria língua-alvo (como veremos no capítulo 4); em terceiro lugar, a Hipótese Contrastiva não dá conta de esclarecer por que os alunos com uma mesma língua materna muitas vezes não cometem o mesmo erro na língua estrangeira; e por último, existem erros constantes e regulares na L2 ou LE, para os quais, entretanto, não se consegue achar explicação de causa na L1. Além disso, se os argumentos dessa tese procedessem sem objeção, as dificuldades de alemães aprendizes do português deveriam ser as mesmas que as dos brasileiros que aprendem alemão, uma vez que, através do contraste, independente da direção, se identificariam as mesmas diferenças. Todavia, esse não é o caso.

Essa tese, tão influente e difundida ainda hoje, é um tanto unilateral e não leva em consideração fatores como a atitude, a motivação, a idade e as condições socioculturais, bem como o professor, o método e o material didático. Além disso, acredita-se que através do contraste, ou seja, da comparação, se possam prever e evitar erros, o que na verdade não é possível como estudos mais tarde o comprovaram: "Ein solcher Mechanismus würde zwar zu irgendwelcher Generalisierung führen, aber nicht garantieren, dass der Lerner die richtigen Generalisierungen findet' (FELIX 1985: 130).

A Hipótese Contrastiva foi duramente criticada, e concluiu-se que, se as crianças cometem erros quando da aquisição de sua primeira língua, mesmo sem poder recorrer a uma língua aprendida anteriormente, então seus erros não podem ser oriundos de interferências interlinguais, mas sim de mecanismos intralinguais. A aquisição de outras línguas (não maternas) 
deve, então, se desenvolver dessa mesma forma. Além disso, a possível influência da L1 ganhava muito destaque nessa tese contrastiva, pois se acreditava que "the habits of the L1 would be carried over into the L2" (ELLIS 1994: 29). Naturalmente, os elementos da língua materna são de grande importância, mas são apenas uma parte de todo um processo extenso e complexo.

A Hipótese de Identidade recorre, então, à teoria cognitiva de Chomsky ${ }^{4}$ sobre a gramática gerativa, segundo a qual se afirma que o ser humano possui uma gramática universal inata e implícita, que torna possível o aprendizado de línguas. A partir disso, desenvolveu-se a idéia de que o homem seria biologicamente pré-programado para a aquisição de línguas, e todo o processo desse tipo seguiria uma determinada seqüência de desenvolvimento, ou seja, ocorreria simplesmente porque o aluno é propenso a isso - igualmente na L1, na L2 ou em LE.

DULAY \& BuRT (1974) dedicaram-se intensivamente aos estudos da Hipótese de Identidade, a fim de comprovar que as influências da língua materna não são tão importantes quanto se acreditava na Hipótese Contrastiva. A tese, também chamada de "L1=L2", defende a posição de que a aquisição de uma L1 e a aquisição de uma L2 não se dão de formas diferentes, pois o aluno ativa, em ambos os casos, os processos mentais naturais e intrínsecos que determinam as estruturas e seqüência de desenvolvimento específicas para o aprendizado. Segundo os pressupostos dessa tese, as interferências não desempenham grande função, já que o aprendizado de uma segunda língua não depende e nem deve ser diferenciado a partir da L1 que se domina (cf. Wode 1985: 12).

De acordo com a Hipótese de Identidade, então, os erros na aquisição da primeira língua resultam da estrutura da própria primeira língua; da mesma forma, os erros no aprendizado de uma L2 são determinados pelas estruturas da L2, e não pelas da L1 (cf. BAUSCH/KASPER 1979: 9). A partir disso, outros fatores internos e externos também não são levados em consideração, uma vez que a seqüência - determinada neurologicamente - será

4 Chomsky já havia se posicionado contra Skinner, defensor da Hipótese Contrastiva, e contra as idéias behavioristas (cf. CHOMsky 1959). 
inevitavelmente seguida (cf. STEINMÜLLER 2001: 14). Resumindo, a aquisição ou aprendizado de uma língua (L1, L2 ou LE) é visto, exclusivamente, como um processo criativo, que ocorre entre o Input (informação recebida) e o Intake (informação já filtrada e trabalhada), e é monitorado pelo próprio aluno (Dulay/Burt 1974: 97).

Foi averiguado com pesquisas, que esta tese também não é suficientemente abrangente. Seu processo contempla determinadas estruturas, mas a regularidade esperada não foi comprovada em todas as áreas e níveis lingüísticos. ${ }^{5}$ A fim de comprovar que a Hipótese Contrastiva era unilateral, por se ater exclusivamente a uma única fonte de erros (no caso, a L1), a Hipótese de Identidade cometeu o mesmo erro ao fixar-se no aspecto intralingual como único mecanismo para a aquisição de uma língua, como se esse procedimento fosse a única possibilidade de o aluno exercer um papel ativo num processo criativo de aquisição lingüística (cf. ScHLOTER 1992: 16). Além disso, uma ou outra expressão sempre terá que ser esclarecida a partir das transferências da L1; esse processo, porém, é totalmente recusado pela Hipótese de Identidade. Aliado a isso - e como já foi dito - a tese não prevê os fatores extralingüísticos em sua análise.

A outra grande tese é a Hipótese de Interlíngua. Seus pressupostos ganham cada vez mais lugar e reconhecimento na teoria, pois em comparação com as outras teses, essa consegue ser mais abarcadora e mais completa. Ela lança mão de elementos das duas outras teses, adicionando a eles um foco mais intenso nos aspectos da cognição e da psicologia - embora se tenha como objetivo, não mais descrever formalmente o produto, mas sim os fenômenos que levaram a ele (cf. Schloter 1992: 4).

O termo Interlanguage (interlíngua) foi criado e aplicado pela primeira vez por SELINKER (1972) e denomina uma "língua intermediária" desenvolvida pelo aluno quando do aprendizado da língua, ou seja, um sistema de transição entre elementos da língua-alvo já adquiridos e a língua-alvo final propriamente dita. Ela também é chamada de "Interimsprache" (RAABE 1974), "Lernersprache” (KIELHÖFER 1975) ou “idiosyncratic dialect” (CORDER 1971).

Para a descrição das lacunas dos estudos de DuLAY \& BuRT e críticas à Hipótese de Identidade, vide Натсн (1983) e McLaughlin (1987). 
Não se trata necessariamente de sinônimos, mas nesse caso os termos denotam a mesma estratégia. A diferença básica é que "Interimsprache” e "Lernersprache" prevêem os fatores idade, pré-conhecimento em L1, préconhecimento em L2, domínio de outras línguas estrangeiras, tempo de aprendizado, contexto social, sob a perspectiva da aula de língua estrangeira (vide KASPER 1981: 13).

Vogel (1990: 13) define Lernersprache como "Sprachgebilde, das sich in einem Fremdsprachenlerner infolge Konfrontation mit qielsprachlichen Daten herausbildet, ohne dabei jedoch völlig mit der jeweiligen Zielsprache identisch zu sein." ELLIS (1994: 30/31) descreve o termo, de forma mais ampla, como "the interim grammars which learners build on their way to full target language competence" e acrescenta que a interlíngua possui três fases: innovation (receber novas informações lingüísticas), elaboration (trabalhá-las, descobrir como usá-las), e revision (adaptálas, comprovar sua validade).

O interessante na teoria de Interlíngua é que o aluno é visto como coresponsável para o sucesso do aprendizado, e não apenas como agente passivo, que só se deixa influenciar. Segundo a Hipótese de Interlíngua, o aprendizado de uma língua é influenciado predominantemente por fatores individuais, pessoais (cf. STEINMÜLLER 2001). Com isso, os fatores internos e externos, sobretudo os psicológicos e os sócio-situacionais, desempenham uma grande função no processo, mas o fator determinante é o aprendiz, que trabalha esses aspectos como bem quer. A interlíngua é o ponto principal.

Essa tese parece ser mais abrangente do que as outras duas, porque ela também trabalha com características daquelas, sem ser unilateral. Enquanto a Hipótese Contrastiva e a Hipótese de Identidade favorecem determinadas linhas e negam outras por completo, a Hipótese de Interlíngua se utiliza de aspectos das duas teorias anteriores simultaneamente. $\mathrm{Na} \mathrm{Hi}$ pótese de Interlíngua se fala, assim como na Hipótese Contrastiva, de transferências da língua materna, porém sem que essa ganhe a importância total, mas também sem ignorar esse processo. Para essa tese o processo de aprendizado de uma língua consiste em um processo criativo - como na Hipótese de Identidade -, sem que, contudo, a seqüência de desenvolvimento seja marcada apenas por ele. A Hipótese de Interlíngua aceita que o aprendizado de uma língua estrangeira seja tanto um fenômeno interlingual (entre 
duas ou mais línguas) quanto intralingual (leva fatores da língua-alvo em consideração, como complexidade, irregularidade, arbitrariedade e freqüência) (cf. KIELHÖFER 1995: 35).

Os erros não são o principal tema da Hipótese de Interlíngua: todo e qualquer tipo de produção por parte do aprendiz deve ser considerado. Segundo as regras dessa tese, toda a produção é correta aos olhos do aluno, pois ela é registrada pelo aluno em sua interlíngua como válida.

\section{O Conceito "Interferência"}

"Interferência" não deve ser entendida como o termo principal para o aprendizado de línguas estrangeiras; é, porém, sem dúvidas, de grande importância, e por isso será cuidadosamente definida e discutida.

O termo Interferência, com o mesmo significado, tem (no mínimo) três diferentes aplicações na lingüística. No que concerne ao contato lingüístico, interferência denota o contato intenso entre duas ou mais línguas, que ao longo do tempo e devido ao uso concorrente e alternado, acabam se misturando (vide WeINREICH 1967 e WandruszKa 1979). Na Hipótese Contrastiva, acredita-se que toda a expressão errada na língua estrangeira seja uma interferência. Na Hipótese de Interlíngua, contudo, interferência significa, ao contrário das outras definições, um processo mais complexo e diversificado de influência sobre a língua a ser aprendida, sem ser tão vaga como na Hipótese Contrastiva - é apenas um fenômeno dentre outros.

Nos três casos, o termo carrega o significado de influência lingüística, entretanto em processos diferentes e com características diferentes, ou seja, eles são levados em consideração de formas variadas. Com o termo "interferência" entende-se, primeiramente, influência, trazida através de um processo de transferência. Transfer, por sua vez, denota a transferência de unidades de uma língua. Por isso, muitos teóricos costumam denominar transfer como um processo e interferência como seu resultado (cf. EHNERT 1989; WeINREICH 1967; Wode 1985). Com isso, todo o tipo de influência interlingual (bem como intralingual) pode ser classificado como interferência, independente de ser "positiva" ou "negativa", ou de trazer benefícios ou malefícios ao aprendizado. 
Segundo JuHÁsz (1970), interferência é “die durch die Beeinflussung von anderen sprachlichen Elementen verursachte Verletzung einer sprachlichen Norm, bzw. der Prozess der Beeinflussung." Vogel \& Vogel (1975: 100) apontam, porém, para o fato de transfers não serem vistos, necessariamente, como algo negativo no aprendizado de língua estrangeira, pois o processo é um sinal para conhecimento adquirido e desenvolvimento ativo.

Interferências são conceituadas, de forma geral, como influências, das quais resultam erros. No entanto, nem toda interferência causa erros, assim como nem todo erro remete a uma interferência. Os termos "erro" e "interferência" não devem ser vistos como sinônimos. As interferências são fatores lingüísticos e pragmáticos, que influenciam o aprendizado de uma língua (de forma positiva ou negativa), e são - quando corretos difíceis de serem reconhecidos na interlíngua. Os erros, por sua vez, são desvios da norma descritiva, que dificultam o aprendizado. Eles estão presentes na interlíngua, mas só recebem importância sob o olhar do professor, pois ele aguarda sempre determinadas estruturas fixas por parte de seus alunos.

Para a autora, interferência é uma transferência interlingual e intralingual de estruturas de uma língua (inclusive da língua materna) no sistema da nova língua, e que pode a partir disso, causar erros. Entretanto, não se pode traçar um paralelo entre os dois conceitos. Pode ser que muitos erros sejam interferências, mas sua origem (L1, etc) é de se discutir, já que a L2 também serve como fonte para interferências (cf. KIELHÖFER 1975: 95). Além disso, como já afirmamos anteriormente, as interferências intralinguais são de igual relevância na interlíngua, pois esses mecanismos de transferência lingüística pertencem à estratégia de aprendizado do aluno. Enquanto o transfer é caracterizado por ser um processo de transferência (ou seja, consciente), a interferência deve ser entendida como uma estratégia de aprendizado (ou seja, consciente ou inconsciente).

Os alunos constroem suas estratégias como procedimentos cognitivos a serem aplicados no processo de assimilação, controlando toda a aquisição lingüística. Criam-se, então, hipóteses de uso para as informações adquiridas, a partir de estruturas já internalizadas (independente de sua origem) e do input recebido. O aprendiz procura, com isso, utilizar-se das informações de acordo com as suas regras, de acordo com o que ele considera 
correto a partir de sua experiência. Dependendo da reação obtida do seu interlocutor (no caso, do professor), ele decide "salvá-la" ou "deletá-la" de sua competência, de sua interlíngua.

As estratégias também podem ser do tipo emocional e influenciam, então, não com elementos lingüísticos, mas com características externas, nos momentos da aquisição, da decisão por "salvar" ou "deletar", da gravação da informação e da integração dessa no sistema da língua-alvo. Através disso, pode-se concluir que o transfer ocorre no processo lingüístico, mas as interferências devem ser entendidas como todo tipo de influência lingüística e extralingüística.

\section{Os alunos bilíngües pesquisados}

Com a imigração em massa de falantes de língua alemã para o Brasil no século XIX, também a língua alemã entrou no Brasil de maneira forte. Os muitos dialetos daquela época foram trazidos para o Brasil, onde foram confrontados uns com os outros. Em colônias extremamente homogêneas, esse aspecto histórico-lingüístico não consistiu, a priori, em nenhum fenômeno; em colônias heterogêneas, entretanto, os dialetos foram se misturando ao longo dos anos. Além disso, objetos e seres novos, ou até então desconhecidos pelos imigrantes, deveriam ser nomeados. Aliado a isso, houve ainda o contato lingüístico com outros idiomas de imigrantes, mas sobretudo com o português, o que levou a empréstimos e à mistura. Esses três aspectos contribuíram diretamente para que ocorressem mudanças lingüísticas com as variedades de "alemão" que chegaram no Brasil. Do contato lingüístico entre a coiné dos dialetos com (principalmente) o português, aliado ao desenvolvimento natural de uma língua viva, originou-se uma variedade lingüística própria e característica de regiões do sul do Brasil, a qual se dá o nome de "hunsrückisch" (cf. Altenhofen 1996).

O termo "hunsrückisch" remete à região do Hunsrück, na Alemanha, de onde veio a maioria dos imigrantes de língua alemã dessas colônias onde hoje se fala o hunsrückisch. O termo é utilizado, porém, para denominar apenas essa variedade (e suas variações) do sul do Brasil. Na Alemanha, o dialeto falado na região do Hunsrück pertence ao grupo do Rhein-MoselFränkisch (entre as delimitações do Rhein-Fränkisch e do Mosel-Fränkisch), 
variedade dialetal localizada entre os rios Reno e Mosela (cf. KÖNIG 2001, Ziegler 1996). "Hunsrückisch" vai caracterizar sempre o assim chamado "alemão brasileiro", e nunca o dialeto original falado na região alemã de onde vieram esses imigrantes.

O dialeto dos imigrantes do Hunsrück (o Rhein-Mosel-Fränkisch), por ser o da maioria, se impôs aos outros nessas regiões, quando do processo da mistura. Ao resultado que temos hoje, após o processo de variação, contato, mistura e mudança lingüística, dá-se o nome de hunsrückisch. Não se trata, entretanto, da única variedade lingüística de origem germânica do sul do Brasil: encontramos aqui também o westfaliano, o pomerano, o bávaro, dentre outros. "Hunsrückisch" denomina as variedades brasileiras atuais de base francônio-renana. Ele vale como um conceito-teto para todas essas variedades, uma vez que, apesar de uma estrutura macro semelhante, podese constatar, de região para região, diferenças lingüísticas sutis entre as formas. Todas são chamadas, porém, de hunsrückisch.

A língua materna dos alunos pesquisados em duas escolas no sul do Brasil é, ao lado do português, o hunsrückisch. Essa variedade lingüística traz aspectos semelhantes ao alemão-padrão, mas possui já estruturas diferenciadas daquele, embora também siga determinadas regras gramaticais elas são, contudo, naturais, e muitas diferem do Hochdeutsch (alemãopadrão).

No seu doutorado, a autora procurou identificar interferências da língua materna no aprendizado do alemão como língua estrangeira no Brasil. O fato de haver dois contextos bem distintos no país - de um lado o contexto monolíngüe e do outro lado um contexto bilíngüe - contribuiu para a metodologia da análise, uma vez que as diferenças entre as línguas serviriam de parâmetro para a averiguação das produções e dos resultados dos testes.

Foram selecionadas três escolas de $\mathrm{DaF}$ : em um contexto monolíngüe, a saber, no Rio de Janeiro, o Colégio Cruzeiro; no contexto bilíngüe, o Colégio Teutônia e o Instituto de Educação Ivoti, ambos localizados em contextos de contato lingüístico hunsrückisch-português no Rio Grande do Sul (Teutônia e Ivoti respectivamente). Apesar de estarem em contextos diferentes, as três instituições de ensino apresentam, praticamente, as mesmas características, tendo perfis muito semelhantes. As três são escolas de 
alemão como língua estrangeira (ou seja, elas oferecem a língua alemã como primeira língua estrangeira no currículo obrigatório, na maioria das vezes já a partir do jardim da infância), têm um grande número de alunos e são ótimas escolas, de renome em seus contextos específicos. Trata-se de escolas privadas, cujos professores tiveram uma formação semelhante e utilizavam na época o mesmo material escolar (Wer, Wie, Was) - sendo o método também semelhante (método comunicativo com perguntas indutoras, ênfase na gramática, aulas alternando entre o alemão e o português).

A pesquisa contou com a participação de 382 alunos. Foram feitas entrevistas, que visavam a traçar o perfil dos alunos de cada escola (informações pessoais, atitudes, crenças e sentimentos lingüísticos) e realizados testes para avaliar os conhecimentos nas quatro habilidades e averiguar os elementos da interlíngua.

Depois de uma entrevista com os alunos, pudemos averiguar ainda, que todos eles são brasileiros, que começaram a aprender o alemão-padrão na escola, sem manter qualquer outro contato com essa variedade da língua fora da escola. Eles gostam de aprender a língua por motivos diferentes, mas nunca estiveram na Alemanha.

$\mathrm{O}$ único fator, que à primeira vista pôde ser analisado como diferença entre as três escolas, foi a situação bilíngüe desses alunos das escolas do Rio Grande do Sul, em comparação com os alunos do contexto do Rio de Janeiro, que possuíam apenas o português como língua materna. Claro que há a já citada diferença de contextos (cidade grande - cidade interiorana), mas como a análise não queria julgar comportamento ou mentalidade, mas sim propriedades pessoais de aprendizado de língua estrangeira, não demos peso a esse fato. A diferença de contexto justamente nos possibilitava a diferença de status lingüístico bilíngüe x monolíngüe. Se analisássemos uma escola como o Centro de Ensino Pastor Dohms, de Porto Alegre, não teríamos as mesmas diferenças em comparação com os alunos do Rio de Janeiro. No interior, as línguas de imigração estão mais conservadas. Por isso escolhemos escolas que tivessem perfis muito semelhantes, apesar dos contextos diversos, para que o fator bilingüismo fosse praticamente o único diferencial relevante nesta análise.

Os testes comprovaram, porém, que as interferências não são oriundas apenas da L1 e que, mesmo provenientes da língua materna, elas não se 
dão da forma que se costuma esperar (como determinado na Hipótese Contrastiva). Os melhores exemplos puderam ser levantados no contraste entre os contextos monolíngüe e bilíngüe (português-hunsrückisch), como veremos a seguir nos quatro exemplos selecionados.

\section{Análise prática}

Como dito, foram feitas entrevistas e testes escritos com os 382 alunos.

Esses testes foram analisados, buscando reconhecer e tentar identificar a possível influência da língua materna. Essa, porém, nem sempre se deixa perceber de forma clara. Partíamos, portanto, de argumentos prós e contras (imparcialmente), procurando ver qual teria mais plausibilidade. Como afirma KIELHÖFER (1975: 78), as análises de interferências devem ser feitas aliadas a conceitos como "menos provável", "provável", "mais provável” e "quase certo", já que a causa de um desvio (ou de um acerto), só se identifica hipoteticamente. Portanto, utilizamo-nos também de comparações entre os resultados do contexto monolíngüe e do bilíngüe. Entretanto, temos que ressaltar que não se trata de comprovações e verdades absolutas. Procuramos apenas fazer uma análise que levasse vários fatores em consideração.

Nosso objetivo, como descrito na introdução, não é negar as interferências, mas sim tentar analisá-las de uma forma diferente. Não vemos problemas em trabalhar com interferências, só acreditamos que o puro contraste, a pura comparação com a língua-alvo não seja totalmente satisfatório. Relatamos aqui, então, os passos de nossa análise, que tentava sair do ponto comum de "se a língua materna é diferente, ocorrerá erro" e que ao mesmo tempo não queria ignorar o fato de a L1 também influenciar. Por isso, nossa crença se assemelha à Hipótese de Interlíngua que, mesmo tendo idéias chomskyanas e traçando algumas comparações, busca ser diferente por aceitar mais possibilidades de análise.

Nossas análises são, com isso, apenas uma das possibilidades, levando em consideração os fatores internos (aspectos cognitivos, empatia, sentimentos, motivação) e externos (aspectos sociais, todas as formas de input, tais como livros didáticos, professores e aulas, e a interação prática com a língua-alvo), averiguados através de observações de aula, entrevistas, estu- 
dos históricos e análise dos contextos. Preocupamo-nos, além disso, em não analisar apenas os desvios, mas também em nos questionarmos a respeito da ausência desses - conseqüentes acertos. O objetivo não é encontrar as respostas absolutas, nem formular teorias, mas sim arriscar palpites para comprovar ou descartar hipóteses que não dão conta de explicar o fenômeno, que deixem dúvidas em aberto.

\section{a) Mein Hobby ist tv *olbieren (Mein Hobby ist fernseben / Fernsehen gucken)} Sie haben *brigiert (Sie haben gestritten)

Esses exemplos não proviriam, à primeira vista, de influência do hunsrückisch, já que os verbos alemães "gucken" e "streiten" existem na variedade do sul do Brasil - enquanto *olhieren e *brigieren não. Poder-se-ia tratar de interferências do português (dominado pelos dois grupos), uma vez que nesse idioma há os verbos "olhar" e "brigar", e os alunos poderiam ter utilizado simples e estrategicamente o sufixo alemão -ieren de forma "hipergeneralizada" através de analogias (português "produzir" = alemão produz̧ieren; português "comentar" = alemão kommentieren; então, português "olhar" = alemão *olbieren).

O mesmo não acontece, entretanto, com os alunos monolíngües (o que, na verdade, seria de se esperar se só levássemos em conta os preceitos da Hipótese Contrastiva). Só se observou uma forma dessas no contexto monolíngüe fora dos testes, enquanto dois alunos conversavam entre si. A expressão, porém, foi usada de forma irônica, fazendo-se piada metalingüística, uma vez que era consciente aos alunos que tal forma não existia, e eles riam disso. Nos testes, eles tiveram a oportunidade de aplicar essa estratégia, sobretudo no exercício de descrição de uma gravura, já que lhes faltava o vocabulário adequado, mas mesmo assim ninguém o fez.

Todavia, os alunos do contexto bilíngüe se utilizaram dessa estratégia quando a palavra "streiten" lhes faltou - e isso ocorreu várias vezes. Não se poderia, entretanto, falar de interferência morfológica ou mesmo lexical por parte do hunsrückisch (uma de suas L1), uma vez que streiten pertence ao seu vocabulário. E para ser interferência do português (a outra L1), por que os alunos monolíngües não o fizeram? 
Esses questionamentos levaram-nos a uma análise provável, levando em conta a história e as características lingüísticas do hunsrückisch, de que a interferência dessa L1, neste momento, teria ocorrido sutilmente no processo de percepção da língua-alvo. Como na evolução do hunsrückisch esses fenômenos ocorreram diversas vezes, os alunos teriam a impressão, ou mesmo a certeza, de que eles também podem proceder dessa forma com a língua. A língua materna não transfere aqui o morfema ou o lexema, mas sim a "permissão" de o criarem. Essa interferência extralingüística ocorre, na interlíngua do aluno, no plano da aquisição, e não no plano da aplicação.

\section{b) Mein Hobby ist tv cucan (Mein Hobby ist Fernsehen gucken)}

O fenômeno que ocorre com esse exemplo, porém, é outro. O verbo gucken não é encontrado em material didático. Nos livros didáticos "sieht man fern" ou, no máximo, "sieht man Fernsehen". Contudo, Fernsehen schauen e Fernsehen gucken são formas raras em livros didáticos escolares de ensino de DaF, apesar de fazerem parte do uso diário normal na Alemanha. Com isso, os alunos que só têm contato com a língua alemã em sala de aula desconhecem o verbo.

Em contrapartida, os alunos do contexto bilíngüe estudado utilizaram freqüentemente essa forma em seus testes. $\mathrm{Na}$ análise, pudemos averiguar, então, que aqui deve se tratar de um fenômeno de interferência da língua materna hunsrückisch, já que essa forma está no seu paradigma de vocabulário a ser utilizado no "alemão". ${ }^{6}$ Eles conhecem o verbo através da L1 semelhante à LE.

Essa interferência da língua materna pode se tornar mais provável quando reparamos que o fenômeno não ocorre com os alunos do contexto monolíngüe, ou seja, se usarmos essa comparação como parâmetro. Ele pertence exclusivamente à interlíngua desses alunos bilíngües, e só por eles é utilizado como estratégia lingüística. O processo de transfer já se dá, na

6 Lembramos aqui que, para os falantes de hunsrückisch, o que eles falam é "alemão". 
verdade, na língua-alvo (os lexemas são selecionados do paradigma "alemão"). O fato de esse lexema pertencer ao paradigma da interlíngua e ser tido como válido, pode ser uma interferência da língua materna. Essa interferência seria lingüística, já que o verbo foi emprestado da L1; a validez creditada ao processo seria, contudo, um fenômeno extralingüístico.

c) Plural (-s versus -er, -e, -en etc.)

Um caso constante foi a forma "* Schwesters" para o plural de Schwester (ao invés de Schwestern) e de "Tigers" para o plural de "Tiger" (no lugar de Tiger mesmo). Tal fenômeno pode ser uma hipergeneralização na própria L2 (como a língua alemã possui muitas possibilidades para a formação do plural, entre eles o não tão freqüente morfema $-\mathrm{s}$, o aluno escolheria um dos modelos para aplicar com mais freqüência em caso de dúvida) ou interferência da língua materna propriamente dita (no português a formação do plural se dá com -s). Fazendo o advogado do diabo, arrisca-se supor que, se o fenômeno fosse exclusivamente uma interferência da língua materna, como explicar que os alunos monolíngües tenham criado, para o plural de Stubl, a forma "*Stuble" (algo como "*Stubls" não apareceu uma só vez)? Da mesma forma como "*Bruders" também não foi utilizada. Para tal, todos os alunos usaram a forma padrão Brüder (isso já mostra, por exemplo, como os desvios e acertos não podem ser previstos apenas através da comparação).

Para "Bahn", por exemplo, surgiu no teste de um aluno monolíngüe a forma "*Bähne", o que soa para ele, provavelmente, muito lógico (se Schwamm $>$ Schwämme; Hahn > Häbne; Kran > Kräne; então Babn > *Bähne).

Os alunos procuram, na própria L2 ou na própria LE, a forma que melhor cabe naquilo que ele quer dizer, e para isso eles se utilizam da lógica de sua interlíngua e da sua intuição lingüística. Não parece se tratar aqui de uma transferência, mas sim de um fenômeno da interlíngua (aquisição de L2 como um processo criativo, o que também propõe a Hipótese de Identidade).

Não seria de se admirar que a forma "* Schwesters" tenha aparecido também no contexto bilíngüe. Se pensarmos que essa palavra não pertence 
ao hunsrückisch, uma vez que nessa variedade se faz uso da forma "irmã", emprestada do português, os alunos não têm em sua L1 parâmetros para a construção de seu plural em alemão, e estão na mesma situação que os alunos monolíngües: só podem recorrer, se for o caso, ao português. $\mathrm{O}$ fenômeno, portanto, é o mesmo.

\section{d) Ich habe zum Zoo gefahren}

De acordo com uma análise contrastiva, poder-se-ia dizer que os alunos se confundem na hora de usar os verbos auxiliares "baben" e "sein", porque essa estrutura não se faz presente no português, ${ }^{7}$ e teríamos que constatar um caso de interferência da língua materna. Todavia, não quisemos ser simplistas, e procuramos também outras possibilidades. Provavelmente seja devido ao hunsrückisch o fato de os alunos bilíngües não terem apresentado esse desvio. Contudo, no contexto monolíngüe, é muito difícil de aceitar que o português contribua de alguma forma para essa estratégia. A consideração seria até plausível, se não fosse este questionamento: se a língua portuguesa não possui essa estrutura com essa semântica, como ela pode transferir e causar essas interferências? Isso não é possível conceitualmente. Os alunos têm que ter achado a estratégia em outra fonte, que não na L1, pois aqui, eles dificilmente achariam nas suas formas analíticas parâmetros para tal.

O caso seria interferência, se os alunos, por exemplo, soubessem falar italiano. Esse idioma também apresenta estruturas analíticas de passado, compostas por verbo auxiliar + verbo principal na forma de particípio. Para tanto, a língua se vale, como no alemão, de dois verbos auxiliares, a saber, essere (ser, estar) e avere (ter), utilizados alternadamente em casos específicos. Os alunos estariam acostumados à estrutura. Quando o aluno quisesse formar a frase "Ich bin geschwommen" ("Eu nadei”) em alemão, por

$\mathrm{Na}$ verdade, a língua portuguesa até possui uma estrutura semelhante à alemã para expressar passado, como "ter feito" (além de outras formas analíticas, como para o Pretérito mais que Perfeito, o Futuro do Presente e o Futuro do Pretérito). A semântica, no entanto, é outra. 
influência do italiano, que só oferece para o verbo nadar (nuotare) a formação de passado com o verbo avere (Io ho nuotato), ele se deixaria influenciar pela língua estrangeira já aprendida anteriormente e faria a frase "Ich habe geschwommen". 8

Entretanto, esse não é o fato. O citado desvio da norma padrão ocorrido nos testes não seria, na verdade, para os alunos do contexto monolíngüe, uma interferência, nem de L1 e nem de L2. Trata-se de mais uma peculiaridade da língua alemã, com a qual os alunos ainda não sabem lidar bem. A estrutura ainda não está presente na sua competência lingüística. A interferência (lingüística) seria na própria LE, quando os alunos buscam no paradigma da LE por uma solução.

\section{Considerações finais}

Com os exemplos apresentados, vimos que a língua materna não é o único fator que influencia o aprendizado de uma língua - diferentemente do que prega a Hipótese da Análise Contrastiva. É muito interessante observar, porém, como a língua materna, mesmo não agindo sozinha, exerce influência, de diversas maneiras, no aprendizado de uma língua estrangeira - ao contrário do que afirmava a Hipótese de Identidade. Também outras línguas já dominadas e a própria língua-alvo contribuem para a formação da interlíngua dos alunos e, conseqüentemente, para a paulatina aquisição da nova língua. Com isso, através dos exemplos expostos, apesar do número reduzido para o presente artigo, pôde-se confirmar a maior validade da Hipótese de Interlíngua em comparação com as outras teses apresentadas para esse tipo de análise que nós desenvolvemos.

8 Trata-se de uma frase gramaticalmente correta, por isso reforçamos: interferência não significa apenas influências negativas. No citado caso, porém, tem-se o agravante de que a forma com o haben, apesar de correta, não é comumente usada pelos alemães, o que a torna um desvio estilístico. Segundo a gramática, contudo, o Perfekt de schwimmen (nadar) em alemão alterna entre haben e sein, dependendo do foco do movimento (Duden 4 2005: 472), ou da conotação de deslocamento para um objetivo x movimento em um determinado lugar, sem um alvo (Dreyer/Schmitt 2004: 63). 
Não há, entretanto, como já fora mencionado, uma verdade absoluta no que diz respeito a meios de análise. $\mathrm{Na}$ maioria das vezes é necessária uma combinação de vários fatores, a L1 inclusive, para se chegar à conclusão da melhor análise a ser feita. Mesmo assim, como prega a Hipótese de Interlíngua, mesmo sem que a L1 seja responsável por tudo o que acontece na L2, ela também deve ser levada em consideração, bem como os fatores internos e externos relacionados ao processo.

Como se pôde perceber através dos testes dos alunos bilíngües, em comparação com os dos monolíngües, a língua materna não se manifesta somente no âmbito lingüístico, mas também no extralingüístico, pondo atitudes, macro-estruturas, estratégias emocionais e até mesmo valores à disposição para serem transferidos para o uso na LE.

No caso do hunsrückisch como uma das línguas maternas e do aprendizado especificamente do alemão-padrão como língua estrangeira em salas de aula, isso implica em uma análise maior por parte dos professores no que diz respeito à interlíngua dos alunos. Ela deve ser mais bem trabalhada, observada e até mesmo aproveitada como substrato para a aula de LE. Simplesmente traçar comparações entre os dois sistemas lingüísticos para determinar as interferências, de acordo com o que prega a Hipótese Contrastiva, não é, como vimos, um procedimento eficaz, pois sozinha não teria dado conta de explicar nenhum fenômeno (nem mesmo de forma especulativa, como permite a Hipótese de Interlíngua). A interlíngua não pode ser prevista, bem como as interferências - em especial de alunos bilíngües, uma vez que três línguas estão em confronto na mente do aluno.

O método mais ideal ou a melhor forma de se trabalhar com a questão bilíngüe em sala de aula (em especial em contextos de contato hunsrückisch-português), ainda é um campo a ser mais bem analisado e discutido. Queríamos, com este trabalho, dar um impulso, chamando a atenção para mais aspectos. Há, no entanto, ainda muito trabalho pela frente.

\section{Referências bibliográficas}

Altenhofen, Cléo Vilson. Hunsrückisch in Rio Grande do Sul: Ein Beitrag zur Beschreibung einer deutschbrasilianischen Dialektvarietät im Kontakt mit dem Portugiesischen. Stuttgart, Steiner 1996. 
Altenhofen, Cléo Vilson. "O Conceito de Língua Materna e suas implicações para o estudo do Bilingüismo (Alemão-Português)". In: Martius-Staden Jahrbuch 49. São Paulo, Institut Martius-Staden 2001, 141-161.

Altenhofen, Cléo Vilson. "Der Bilingualismus in Familie, in Schule und in Brasilien". In: Info ARPA / 2002, 5-6.

Altenhofen, Cléo Vilson / Pupp Spinassé, Karen et al. "Fundamentos para uma escrita do Hunsrückisch falado no sul do Brasil". In: Anais do Seminário Internacional Imigração e Relações Interétnicas, XV II Simpósio de História da Imigração e Colonização. São Leopoldo. (no prelo)

BausCH, Karl-Richard / KasPeR, Gabriele. "Der Zweitsprachenerwerb: Möglichkeiten und Grenzen der ,großen’ Hypothesen”. In: Linguistische Berichte 64/1979, 3-35.

Chomsky, Noam. "Review of B. F. Skinner Verbal Behavior". In: Language 35/1959, 26-58.

Corder, S. Pit. "Idiosyncratic dialects and error analysis". In: IRAL 9/ 1971, 161-169.

DreYER, Hilke / SCHMTTT, Richard. Lehr- und Übungsbuch der deutschen Grammatik. Neubearbeitung. Ismaning, Hueber 2000.

Duden Band 4: Die Grammatik. Mannheim u. a., Dudenverlag 2005.

Dulay, Heidi C. / Burt, Marina K. "A new perspective on the creative construction process in child second language acquisition". In: Language Learning 24/1974, 253-278.

Edmondson, Willis J. / House, Juliane. Einführung in die Sprachlehrforschung. Tübingen / Basel, Francke 1993.

EHnERT, Rolf (Org). Einführung in das Studium des Faches Deutsch als Fremdsprache: Handreichungen für den Studienbeginn. Frankfurt am Main, Peter Lang 1989.

ELLIS, Rod. The study of second language acquisition. Oxford, Oxford University Press 1994.

FELIX, Sascha Walther. "Kognitive Grundlagen des Fremdsprachenlernens". In: Goethe-Institut (Org). Lernersprache, München, Kemmler \& Hoch 1985, 107-145. 
FrIEs, Charles. Teaching and learning English as a foreign language. Ann Arbor, University of Michigan Press 1945.

Griesshaber, Wilhelm. Erwerb und Vermittlung des Deutschen als Zweitsprache. Münster, Sprachenzentrum der Westfälischen Wilhelms-Universität Münster 2002.

Hatch, Evelyn. Psycholinguistics: a second language perspective. Rowley, Mass., Newbury House 1983.

Heindrichs, Wilfried / Gester, Friedrich Wilhelm / Kelz, Heinrich P. Sprachlehrforschung: angewandte Linguistik und Fremdsprachendidaktik. Stuttgart, Kohlhammer 1980.

JuHÁsz, Jonas. Probleme der Interferenæ: München, Hueber 1970.

Kasper, Gabriele. Pragmatische Aspekte in der Interimsprache. Eine Untersuchung des Englischen fortgeschrittener deutscher Lerner. Tübingen, Narr 1981.

KIELHÖFER, Bernd. Fehlerlinguistik des Fremdsprachenerwerbs: linguistische, lernpsychologische und didaktische Analyse von Französischfehlern. Kronberg/Ts, Scriptor 1975.

KIELHÖFER, Bernd. "Die Rolle der Kontrastivität beim Fremdsprachenerwerb”. In: DitTmar, Norbert / Rost-Roth, Martina (Org). Deutsch als Zweit- und Fremdsprache, Frankfurt am Main, Peter Lang 1995, 35-51.

Knapp-Potтhoff, Annelie / KNapp, Karlfried. Fremdsprachenlernen und-lehren. Eine Einführung in die Didaktik der Fremdsprachen vom Standpunkt der Zweitsprachenerwerbsforschung. Stuttgart, Kohlhammer 1982.

KöNIG, Werner. dtv-Atlas Deutsche Sprache. München, dtv 2001.

LAdO, Robert. Linguistic across Cultures. Applied Linguistics for language teachers. Ann Arbor, University of Michigan Press 1957.

McLaughlin, Barry. Theories of second language learning. London, Arnold 1987.

Pupp Spinassé, Karen. Deutsch als Fremdsprache in Brasilien: Eine Studie über kontextabhängige unterschiedliche Lernersprachen und muttersprachliche Interferenzen. Berlin, Peter Lang 2005.

Pupp Spinassé, Karen. “Os conceitos Língua Materna, Segunda Língua e Língua Estrangeira e os falantes de línguas alóctones minoritárias no sul do Brasil”. In: Revista Contingentia 1/2006, 51-58. 
Pupp Spinassé, Karen. “As interferências do Hunsrückisch como língua materna no aprendizado do alemão-padrão por descendentes de imigrantes alemães: relatos de pesquisas, projetos e perspectivas". In: Anais do Seminário Internacional Imigração e Relações Interétnicas, XVII Simpósio de História da Imigração e Coloniz̧ação. São Leopoldo. (no prelo)

RAABE, Horst. "Intersprache und kontrastive Analyse". In: RAABE, Horst (Org). Trends in kontrastiver Linguistike 1, Tübingen, Narr 1974, 1-50.

SCHLOTER, Andreas Leonhard. Interferenafehler beim Erwerb des Englischen als Fremdsprache: Ein empirischer Beitrag zur Feblerursachenforschung. München, tuduv-Verl.-Ges. 1992.

SELINKER, Larry. "Interlanguage”. In: IRAL 10/1972, 209-231.

STEINMÜLLER, Ulrich. "Fehler und Fehlerkorrektur im Unterricht Deutsch als Fremdsprache". In: Cadernos de Letras 17/2001, 11-23.

VogEL, Klaus. Lernersprache: Linguistische und psycholinguistische Grundfragen zu ibrer Erforschung. Tübingen, Narr 1990.

Vogel, Klaus / Vogel, Sigrid. Lernpsychologie und Fremdsprachenerwerb. Tübingen, Niemeyer 1975.

WandruszKa, Mario. Die Mehrsprachigkeit des Menschen. München, Piper 1979.

Weinreich, Uriel. Languages in Contact: Finding and Problems. London, Mouton \& Co. 1967.

Wode, Henning. "Zweitsprachenerwerbsforschung im Rückblick”. In: Goethe-Institut (Org). Lernersprache. München, Kemmler \& Hoch 1985, 7-66.

Ziegler, Arne. Deutsche Sprache in Brasilien: Untersuchungen zum Sprachwandel und zum Sprachgebrauch der deutschstämmigen Brasilianer in Rio Grande do Sul. Essen, Die blaue Eule 1996. 